http://dx.doi.org/10.1590/0102-4698131383

\title{
A HISTÓRIA A SER ENSINADA EM SÃO PAULO
}

\author{
Antonio Simplicio de Almeida Neto* \\ Helenice Ciampi**
}

RESUMO: Este artigo discute a proposta curricular São Paulo Faz Escola, implantada nas escolas públicas do Estado de São Paulo em 2008 e em vigor até o momento. Tal proposta unifica e prescreve conteúdos e procedimentos das diferentes disciplinas escolares por meio de materiais didáticos para professores, gestores e alunos, além de vídeos de formação continuada. São analisados os conteúdos da proposta curricular e a materialidade dos impressos didáticos destinados a professores e alunos, observando seus objetivos explícitos e implícitos, as concepções subjacentes de educação e de história, os conceitos mobilizados, suas contradições e as representações referentes aos diferentes sujeitos envolvidos. Destacamos, particularmente, a disciplina escolar história, que é abordada de forma linear, evolutiva e eurocêntrica - bem como os chamados grandes personagens e acontecimentos -, desconsiderando os debates e as iniciativas que vêm ocorrendo nesse campo curricular e historiográfico desde, pelo menos, os anos de 1980.

Palavras-chave: Currículo. Ensino de história. Disciplina escolar. Cultura escolar. Forma escolar.

\footnotetext{
* Doutor em Educação pela Universidade de São Paulo (USP). Professor Adjunto do Departamento de História e do Programa de Pós-Graduação em História da Universidade Federal de São Paulo. E-mail: asaneto@unifesp.com

** Doutora em História pela FFFLCH (USP). Professora Titular da Pontifícia Universidade Católica de São Paulo e do Programa de Pós-Graduação em Educação Historia, Política, Sociedade da (PUC-SP). Membro do Grupo de Pesquisa Historia das Instituições e dos Intelectuais da Educação Brasileira . E-mail: heleciampi@uol.com.br
} 


\section{THE HISTORY TO BE TAUGHT IN SÃO PAULO}

ABSTRACT: This article discusses the curricular proposal "São Paulo Faz Escola", which was implemented in public schools in the state of São Paulo, Brazil, in 2008 and still in action. This proposal unifies and prescribes contents and procedures of different disciplines. It is diffused through didactic materials for teachers, school administrators, and students, as well as through videos on teachers' continuing training. We analyze the subjects' contents on the Curriculum Proposal and the materiality of the educational printed material for teachers and students. For this we observe their explicit and implicit goals, the underlying concepts of education and history, the mobilized concepts, its contradictions, and the representations concerning the different subjects involved. In particular, we emphasize the school subject History, which is addressed in a linear, evolutionary, and Eurocentric way; as well as the adopted approach to the so called major figures and events. This ignores the debates and initiatives that have been taking place in the curricular and historiographical field since, at least, the 1980s.

Keywords: Curriculum. History teaching. School discipline. School culture. School shape.

\section{A HISTÓRIA A SER ENSINADA EM SÃO PAULO}

Passados mais de seis anos da execução da proposta curricular do Estado de São Paulo, o que permite relativo distanciamento, faz-se necessário um novo olhar sobre esse programa, que continua vigendo nas escolas públicas estaduais paulistas. Instituída na gestão José Serra do governo do Estado de São Paulo (2007-2010), quando era secretária de Educação Maria Helena Guimarães de Castro, e tendo continuidade na gestão Geraldo Alckmin (2011-atual), a proposta curricular denominada São Paulo Faz Escola, cuja concepção e cuja coordenação geral estavam a cargo de Maria Inês Fini, anunciava em seu documento de apresentação duas iniciativas:

A primeira delas é realizar um amplo levantamento do acervo documental e técnico pedagógico existente. A segunda é iniciar um processo de consulta a escolas e professores, para identificar, sistematizar e divulgar boas práticas existentes nas escolas de São Paulo. Articulando conhecimento e herança pedagógicos com experiências escolares de sucesso. (SÃO PAULO, 2008a, p, 3).

Propõe, ainda, abordar:

[...] algumas das principais características da sociedade do conhecimento e as pressões que a contemporaneidade exerce sobre os jovens cidadãos, propondo princípios orientadores para a prática educativa, a fim de que as escolas possam se tornar aptas a preparar seus alunos para esse novo tempo. (SÃO PAULO, 2008a, p. 3) 
Observou-se, no período de sua implementação, que não houve consulta aos sujeitos diretamente envolvidos nas atividades escolares - professores, alunos, diretores e coordenadores da rede pública estadual -, e, sim, a consultores, que elaboraram essa proposta curricular sob encomenda ${ }^{1}$.

Com efeito, no início do ano letivo de 2008, as escolas públicas estaduais foram surpreendidas com a notícia de que, doravante, deveriam seguir a nova proposta curricular que se materializava no Jornal do Aluno: São Paulo Faz. Escola - Edição Especial da Proposta Curricular (SÃO PAULO, 2008b), distribuído aos alunos da rede. Num segundo e num terceiro momento, outros materiais didáticos na forma de fascículo foram entregues a professores e alunos, de modo a normatizar, organizar e unificar suas ações pedagógicas. Tratava-se de proposta cujo objetivo precípuo foi, e ainda é, priorizar "a competência de leitura e escrita" (SÃO PAULO, 2008a, p. 3), o que levaria ao inevitável protagonismo dos componentes curriculares língua portuguesa e matemática, em detrimento das especificidades das demais disciplinas escolares.

Nesse artigo, produzido no âmbito do projeto Panorama do Ensino de História, do Grupo de Trabalho (GT) de Ensino de História e Educação da Anpuh Brasil em articulação com os GTs de Ensino das Anpuhs regionais, discutimos a proposta curricular São Paulo Faz Escola nos detendo mais especificamente no que se refere à disciplina escolar história.

\section{DO CURRÍCULO, DA FORMA E DA CULTURA ESCOLARES}

A proposta curricular São Paulo Faz Escola deve ser entendida como currículo pré-ativo, na definição de Goodson (1995, p. 24), em oposição ao currículo ativo ou interativo, que é aquele que ocorre no âmbito da sala de aula e que pode, eventualmente, "subverter ou transcender a fase pré-ativa" (GOODSON, 1995, p. 24), o que não será discutido neste artigo, uma vez que demandaria observar as práticas em sala de aula. No entanto, o estudo desse currículo oficial faz-se necessário para desnaturalizarmos esse procedimento intentado pelo Estado de São Paulo, compreendendo conflitos e discussões inerentes à sua constituição, dos quais é o ponto culminante. Assim, afirma Goodson (1995, p. 24):

Se não analisarmos a elaboração do currículo, a tentação será a de aceitá-lo como um pressuposto e buscar variáveis dentro da sala de aula, ou, pelo menos, no ambiente de cada escola em particular. Estaríamos aceitando como "tradicionais" 
e "pressupostas", versões de currículo que num exame mais aprofundado podem ser consideradas o clímax de um longo e contínuo conflito.

Com esse propósito, procedemos à análise da referida proposta curricular, tendo por base, fundamentalmente, o material produzido pela própria Secretaria de Educação do Estado de São Paulo, constituindo nosso corpus documental: a) Jornal do Aluno: São Paulo Faz Escola - Edição Especial da Proposta Curricular (SÃO PAULO, 2008b); b) Caderno do Aluno e Caderno do Professor: Ciências Humanas e Suas Tecnologias - História, Ensino Fundamental II e Médio; e c) Proposta Curricular São Paulo Faz. Escola. Também foram utilizados relatos coletados em Fórum de Graduação da Anpuh-SP realizado em 2008 e em oficinas para professores da Educação Básica do GT de Ensino de História e Educação da Anpuh-SP (entre 2008 e 2013).

Mais que simples instrumentos da burocracia escolar, tais documentos constituem o aparato escritural da "forma escolar", como propõem Vincent, Lahire e Thin (2001), ao afirmarem que o processo de socialização e, consequentemente, as formas de transmissão de saberes que ocorrem na sociedade das formas orais para formas escriturais foram se transformando lentamente ao longo dos séculos XVI e XVII, até se tornarem hegemônicos, instituindo novas formas de organização do espaço e do tempo que se traduzem na instituição agora consagrada: a escola. Decorrem daí novas formas de relação, agora impessoais, que pressupõem regras escrituradas e que garantem a transmissão desses saberes entre mestres e alunos, com as:

[...] sentenças afixadas, os cartões com o alfabeto ou as sílabas, o quadro, as divisões e a sucessão das partes dos saberes aperfeiçoados pela "conduta", o uso dos sinais, a fixação de um programa cotidiano, semanal e anual, a manutenção de "catálogos" (de recepção, de mudanças de lição, da ordem das lições, das qualidades dos alunos, dos primeiros bancos, dos presentes e ausentes), os educadores dessa escola põem fim ao improviso, que é a características das aprendizagens não institucionais, não sistematizadas, não formalizadas, peculiares das formas sociais orais que colocam em cena determinadas pessoas que adaptam seu saber a situações particulares. (VINCENT; LAHIRE; THIN, 2001, p. 32)

Sobre tais formas de escrituração, lembra Munakata (2010, p. 255) que "aprender os saberes ensinados na escola equivale a ler os textos em que eles estão codificados. Estudar na escola é ler os livros didáticos e demais materiais escolares, em que a escritura predomina", como, podemos acrescentar, as apostilas e, mais recentemente, toda sorte de suportes eletrônicos e novas mídias, cada vez mais presentes nas escolas.

Entre os materiais didáticos estruturantes das práticas escolares na rede pública de São Paulo encontram-se, desde 2007, os 
fascículos Caderno do Professor e Caderno do Aluno, organizando o tempo das lições, dosando os conteúdos, propondo lições, textos, imagens e exercícios, orientando e conduzindo as ações dos professores e dos alunos. Tais materiais, e as práticas que ensejam, no entanto, foram inseridos numa cultura escolar, que, como propõe Julia (2001, p. 10), trata-se de "um conjunto de normas que definem os saberes a ensinar e os comportamentos a inculcar, e um conjunto de práticas que permitem a transmissão desses conhecimentos e a incorporação desses comportamentos", ou, na definição de Viñao-Frago (2007, p. 87):

Conjunto de teorias, ideias, princípios, normas, modelos, rituais, inércias, hábitos e práticas (formas de fazer e pensar, mentalidades e comportamentos) sedimentadas ao longo do tempo em forma de tradições, regularidades e regras de jogo não interditas e compartilhadas por seus atores, no seio das instituições educativas.

Esse autor também aponta os elementos (VIÑAO-FRAGO, 2007, p. 88-89) da referida cultura e os diferentes aspectos implicados que interferem em sua conformação e na dinâmica característica: a) atores (professores, alunos, pais, administração e serviços) e sua formação, sua idade, suas representações, sua composição social, sua carreira acadêmica etc.; b) "discursos, linguagens, conceitos e modos de comunicação" utilizados no meio escolar; c) aspectos organizativos institucionais (práticas e rituais, formas de classificação e avaliação de alunos, organização curricular, hierarquias, organização e usos do tempo e do espaço etc.); e d) "cultura material da escola, seu entorno físico-material e objetos (espaços edificados e não edificados, mobiliário, material didático)".

Desse modo, ampliam-se as possibilidades de análise da proposta curricular São Paulo Faz Escola ao considerarmos que as escolas não se encontram como tábula rasa sujeitas às inscrições efetuadas pela proposta curricular aqui analisada. Pelo contrário, estamos falando de diferentes sujeitos e suas representações, diferentes realidades escolares com seus códigos, rituais e organização, espaços com características e usos específicos, que não se ajustam pura e simplesmente às expectativas oficiais. Isso explica situações em que, por exemplo, como veremos, alguns alunos acessam sites da internet para obter as respostas das questões do Caderno do Aluno, alterando os usos que esse e outros materiais deveriam ter.

Cumpre ainda considerar na análise dos referidos materiais didáticos, notadamente os cadernos do Aluno e do Professor, o que Chartier (1992, p. 221) denomina de "relação triangular", que envolve esses impressos apostilados e que se estabelece em torno de três 
pólos: o próprio texto, o objeto e o ato que o apreende, ou seja, texto, suporte e leitor. Desse modo, deve-se atentar para o fato de que, primeiramente, o texto comporta certos "protocolos de leitura" (CHARTIER, 1992, p. 78), que, por assim dizer, indicam uma "leitura autorizada do texto" (CHARTIER, 1992, p. 215), a qual, no entender de seus autores, seria a mais correta e apropriada para os destinatários de sua produção, ainda que esse produto não tenha um autor específico, podendo ser obra encomendada a um "redator". As estratégias de leitura intentadas pelos autores e editores, segundo o historiador francês, são "explícitas e se fundamentam no discurso (em prefácios, prólogos, comentários e notas), e outras são implícitas, transformando o texto num mecanismo que deve, necessariamente, impor uma compreensão considerada legítima" (CHARTIER, 1992, p. 215).

Faz-se necessária, ainda, a análise do suporte - também interferindo e conduzindo os procedimentos de leitura - no qual se inscreve o texto, que lhe permite ser lido e que invariavelmente escapa às intenções e aos propósitos do autor: capa, leiaute, formato, diagramação, ilustrações, tipos. São aspectos, como alerta Chartier (1991), muitas vezes negligenciados nas pesquisas, mas que "contribuem amplamente para dar feição às antecipações do leitor em relação ao texto e para avocar novos públicos ou usos inéditos" (CHARTIER, 1991, p. 182).

Um terceiro aspecto a ser considerado nessa "relação triangular" é o de que "as significações do texto, quaisquer que sejam, são constituídas, diferencialmente, pelas leituras que se apoderam deles" (CHARTIER, 1996, p. 78), como fruto das diferentes formas de "apropriação" cultural e do texto (CHARTIER, 1996, p. 99; 1992, p. 233; 1991, p. 180) implementadas pelo leitor, indicando a "pluralidade das leituras possíveis do mesmo texto, em função das disposições individuais, culturais e sociais de cada um dos leitores" (CHARTIER, 1996, p. 98). Não obstante a importância deste último aspecto, como afirmado anteriormente, não nos deteremos nas apropriações e nos usos das apostilas por parte de seus leitores (alunos e professores).

Desse modo, nosso estudo pautou-se na análise do conteúdo da proposta curricular e da materialidade dos impressos didáticos a serem utilizados pelos professores e pelos alunos, observando seus objetivos explícitos e implícitos, as concepções subjacentes de educação e de história, os conceitos mobilizados, suas contradições e as representações dos diferentes sujeitos envolvidos. 


\section{DO JORNAL AOS FASCÍCULOS}

O Programa Curricular São Paulo Faz Escola foi criado em 2007 com o propósito de instituir um currículo único para as mais de 5.000 escolas da rede pública estadual de São Paulo, sob a alegação de colocar todos os alunos no "mesmo nível de aprendizado", abrangendo o Ensino Fundamental I e II e o Ensino Médio.

Inicialmente, como mencionamos, a proposta chegou às escolas estaduais através do Jornal do Aluno: São Paulo Faz Escola - Edição Especial da Proposta Curricular (SÃO PAULO, 2008b). Confeccionado em formato tabloide (P\&B, papel branco, 40 páginas, edição de 1.260.000 exemplares), esse material consistia no "pontapé inicial para um importante projeto" nos "primeiros 42 dias de aula", conforme mensagem da própria Secretária de Educação à época, estampada na primeira página da publicação.

Dividida em oito seções por disciplinas ${ }^{3}$, a proposta trazia os respectivos conteúdos em textos, ilustrações e atividades organizados em "fichas", unidades que deveriam ser trabalhadas no referido período. Posteriormente, os professores passaram a receber o Caderno do Professor, na forma de fascículos apostilados por componente curricular, com atividades para cada bimestre letivo, distribuídos em conteúdos dosados com prescrições de atividades por aula; eram 28 cadernos por disciplina nas diferentes séries do Ensino Fundamental II e no Ensino Médio. Em 2009, também os discentes receberam o Caderno do Aluno, cujas atividades propostas e as respectivas respostas são, hoje, amplamente divulgadas em sites na internet ${ }^{4}$. Houve uma estratégia anunciada de implementação progressiva: em 2007, na capital; em 2008, na Grande São Paulo; e, em 2009, em todo o Estado.

Essa proposta curricular continuou vigendo com a entrada de Paulo Renato Souza como secretário de Educação, em 2009, ainda no governo Serra, e permanece com o atual secretário, Herman Voorwald, no governo Alckmin, conforme estampado no site da Secretaria da Educação ${ }^{5}$, onde constam os documentos: Caderno do Gestor, Caderno do Professor, Caderno do Aluno, Proposta Curricular e Currículo, além de Orientações Técnicas na forma de videopalestras com especialistas das diferentes áreas do conhecimento.

A concepção do São Paulo Faz Escola foi de Maria Inês Fini, Guiomar Namo de Melo, Lino de Macedo, Luiz Carlos de Menezes e Ruy Berger, sendo que a autoria dos cadernos de história teve à frente o historiador Paulo Miceli. A Fundação Carlos Alberto Vanzolini, por meio da Gestão de Tecnologias aplicadas à Educação (GTE), geriu a 
"produção e elaboração dos materiais pedagógicos que serviram de apoio a 200 mil professores, 30 mil gestores e 4,5 milhões de alunos" e a edição de, em três anos, "cerca de 300 milhões de exemplares de cadernos de Aluno e mais de 50 milhões de Cadernos do Professor referentes às 13 disciplinas do Ensino Fundamental II e do Ensino Médio", além da formação continuada em cursos por videoaulas, como A Rede Aprende com a Rede e Apoio à Continuidade de Estudos.

\section{DOS PRINCÍPIOS, DOS CONTEÚDOS E DA ESTRUTURA}

Conforme informa a proposta curricular, o São Paulo Faz. Escola foi pensado como um projeto de educação para enfrentar os desafios da sociedade contemporânea, produto da revolução tecnológica e "dos processos políticos que redesenharam as relações mundiais que geraram um novo tipo de desigualdade, ou exclusão, ligada ao uso das tecnologias de comunicação que hoje mediam o acesso ao conhecimento e aos bens culturais" (SÂO PAULO, 2008a, p. 4). Sobre a proposta, o documento ainda registra:

Para que a democratização do acesso à escola tenha uma função realmente
inclusiva não é suficiente universalizar a escola. É indispensável a universalização
da relevância da aprendizagem. [...] O desenvolvimento pessoal é um processo
de aprimoramento das capacidades de agir, pensar, atuar sobre o mundo e lidar
com a influência do mundo sobre cada um, bem como atribuir significados
e ser percebido e significado pelos outros, apreender a diversidade e ser
compreendido por ela, situar-se e pertencer. A educação precisa estar a serviço
desse desenvolvimento, que coincide com a construção da identidade, da
autonomia da liberdade. (SÃO PAULO, 2008a, p. 9)

Nessa perspectiva, a proposta curricular tem como princípios centrais manifestos: a escola que aprende, o currículo como espaço de cultura, as competências como eixo de aprendizagem, a prioridade da competência de leitura e de escrita, a articulação das competências para aprender e a contextualização no mundo do trabalho. A escola que aprende parte do princípio de que ninguém conhece tudo e de que o conhecimento coletivo é maior que a soma dos conhecimentos individuais, além de ser qualitativamente diferente; esse seria "O ponto de partida para um trabalho colaborativo para a formação de uma comunidade aprendente" (SÃO PAULO, 2008a, p. 11).

$\mathrm{Na}$ proposta, afirma-se que gestores, professores e alunos devem recriar o currículo a partir dos seus contextos específicos. Para os chamados gestores, há um caderno complementar de Orientações para a Gestão do Currículo na Escola, segundo o qual se deve observar que: 
O ponto mais importante [...] é garantir que o Projeto Pedagógico, que organiza o trabalho nas condições singulares de cada escola, seja um recurso efetivo e dinâmico para assegurar aos alunos a aprendizagem de conteúdos e a constituição das competências previstas nesta Proposta Curricular. (SÃO PAULO, 2008a, p. 8)

O Caderno do Professor, organizado por disciplina e por bimestre, subsidia

[...] [as] situações de aprendizagem para orientar trabalho (...) no ensino dos conteúdos disciplinares específicos. Esses conteúdos, habilidades e competências são organizados por série e acompanhados de orientações para a gestão da sala de aula, para a avaliação e a recuperação, bem como estratégias de trabalho nas aulas, experimentações, projetos coletivos, atividades extraclasse e estudos interdisciplinares. (SÃO PAULO, 2008a, p. 8)

E, finalmente, dos alunos espera-se:

A autonomia para gerenciar a própria aprendizagem (aprender a aprender) e o resultado dela em intervenções solidárias (aprender a fazer e a conviver) deve ser a base da educação das crianças, dos jovens e adultos, que têm em suas mãos a continuidade da produção cultural e das práticas sociais. (SÃO PAULO, 2008a, p. 10)

Assim, os gestores devem ser "animadores" para que a proposta seja efetivada nos diversos contextos escolares; os professores são orientados para o processo de aprendizagem dentro de seus conteúdos específicos; e os alunos devem gerenciar o que foi aprendido.

Como se percebe, há na proposta um discurso que sugere a intenção de favorecer o protagonismo dos sujeitos escolares no processo educacional. Chama a atenção a vasta utilização de nomenclatura característica da área de administração de empresas, de modo que diretores, coordenadores, professores e alunos tornam-se todos gestores. Diretores e coordenadores fazem a gestão da escola, o professor faz a gestão da aula, e até o aluno fica encarregado da gestão de sua aprendizagem, ou seja, é este que deve, supostamente, empunhar a batuta e puxar os cordões do processo.

Não obstante toda a autonomia anunciada, o Caderno do Professor é uma das principais ferramentas do projeto São Paulo Faz Escola. Nele está a base curricular, "referência comum a todas as escolas da rede estadual" (SÃO PAULO, 2008a, p. 6), que descreve e prescreve os conteúdos disciplinares a serem desenvolvidos em cada série, bem como os demais procedimentos.

A história é denominada, na proposta curricular São Paulo Far. Escola, como disciplina escolar, devendo o professor

extrair conhecimento dos distantes tempos passados. [...] Cabe-lhe acompanhar, sem dirigir, os momentos iniciais da formação da consciência crítica de crianças e adolescentes, a partir de sua experiência cotidiana. Para isso, esperamos que 
ele supere as sempre lembradas formas tradicionais de ensino, que parecem valorizar, sobretudo, o sentimento de pertencer - para servir a uma grande nação, assim como fizeram os heróis ${ }^{7}$ responsáveis por sua construção. (SÃO PAULO, 2008a, p. 41.)

Observando-se o Caderno do Professor da disciplina de história referente aos diferentes anos e bimestres do Ensino Fundamental, notou-se que o tempo proposto para desenvolver as situações de aprendizagem varia entre 7 e 14 aulas, em um total de 24 aulas bimestrais, o que poderia ser bastante razoável. No entanto, manifestações de professores em Fórum de Graduação da Anpuh-SP (2008) revelaram a impossibilidade de executar as diferentes atividades propostas, incluindo-se leitura de textos didáticos, pesquisa em diferentes fontes, montagem de painéis e de álbuns, maquetes, leitura cartográfica, trabalhos em grupo, análise documental, exposições dos trabalhos, entre outros, dentro do tempo previsto. Os professores afirmaram ter que optar ou pelo cumprimento rápido das etapas dentro do tempo proposto sem poderem estimular a criatividade e a reflexão dos alunos ou por respeitar o ritmo dos alunos e utilizar mais aulas que o previsto.

Os conteúdos de história são organizados por temas: quatro por bimestre - com exceção da $1^{a}$ série do Ensino Médio, que foi contemplada com seis temas, o que dá uma média de 15 dias para cada tema. Notou-se que, nos quatro bimestres da $5^{a}$ série até o $2^{\circ}$ bimestre da $6^{a}$ série, a proposta valoriza as temporalidades baseadas na ordenação cronológica sob uma perspectiva linear evolutiva: Pré-História ( $1^{\circ} \mathrm{bim}$.), Antiguidade Oriental ( $2^{\circ} \mathrm{bim}$.), Antiguidade Clássica ( $3^{\circ} \mathrm{bim}$.), Idade Média ( $\left.4^{\circ} \mathrm{bim}.\right)$, na $5^{\mathrm{a}}$ série; seguidas de Idade Média ( $1^{\circ} \mathrm{bim}$.) e Idade Moderna ( $2^{\circ} \mathrm{bim}$.), na $6^{\mathrm{a}}$ série. A partir do $3^{\circ}$ bimestre desta série, é adotada outra abordagem, a da chamada história integrada, que introduz o tempo sincrônico, na qual as histórias do Brasil, da América e da África são articuladas à europeia. Tal perspectiva, ao procurar explicar em um único processo relações de causalidade, contiguidade e simultaneidade no tempo (BRASIL, PCN, 1997), institui novos posicionamentos nas relações espaço/ tempo, muito embora mantenha a lógica de ordenação dos conteúdos sob a perspectiva da linearidade sequencial.

Nos temas previstos para o Ensino Fundamental (EF) - 59 temas - e o Ensino Médio (EM) - 38 temas - na Proposta Curricular do Estado de São Paulo: História, identifica-se uma pequena parcela de conteúdos dedicados à história do Brasil: 22 temas no EF e 8 temas no EM, sendo que, tanto na $5^{\mathrm{a}}$ série quanto na $1^{\mathrm{a}}$ série do Ensino Médio, não aparecem temas referentes à história brasileira.

Os conteúdos propostos, a seriação e a respectiva carga horária são: 
QUADRO 1: Proposta Curricular do Estado de São Paulo: História - Ensino Fundamental

\begin{tabular}{|c|c|}
\hline $5^{\mathrm{a}}$ série - $1^{\circ}$ bimestre: 4 temas principais em 4 situações de aprendizagem & $\mathrm{n}^{0}$ /aulas \\
\hline $1^{\circ}$ Sistemas sociais e culturais de notação de tempo ao longo da história de notação. & 3 aulas \\
\hline $2^{\circ}$ As linguagens das fontes históricas: documentos escritos, mapas, imagens, entrevistas. & 4 aulas \\
\hline $3^{\circ} \mathrm{A}$ vida na Pré-História e a escrita. & 4 aulas \\
\hline $4^{0}$ Memória e História. & 3 aulas \\
\hline Total de aulas no $1^{\circ}$ bimestre & 14 aulas \\
\hline $6^{a}$ série - $1^{\circ}$ bimestre: 4 temas principais em 4 situações de aprendizagem & $\mathrm{n}^{0}$ /aulas \\
\hline $1^{\circ} 0$ feudalismo em suas relações sociais, econômicas, políticas e religiosas. & 3 aulas \\
\hline $2^{\circ}$ As Cruzadas e os contatos entre as sociedades europeias e orientais. & 3 aulas \\
\hline $3^{\circ}$ Renascimento Comercial e Urbano. & 2 aulas \\
\hline $4^{\circ}$ Renascimento Cultural e Científico. & 3 aulas \\
\hline Total de aulas no $1^{\circ}$ bimestre & 11 aulas \\
\hline $7^{\text {a }}$ série - $1^{0}$ bimestre: 4 temas principais em 4 situações de aprendizagem & $\mathrm{n}^{0} /$ aulas \\
\hline $1^{\circ} 0$ lluminismo. & 4 aulas \\
\hline $2^{\circ}$ A colonização inglesa e a independência dos Estados Unidos. & 3 aulas \\
\hline $3^{\circ} \mathrm{A}$ colonização espanhola e a independência da América espanhola. & 1 aula \\
\hline $4^{0}$ A Revolução Industrial inglesa. & 2 aulas \\
\hline Total de aulas no $1^{\circ}$ bimestre & 10 aulas \\
\hline $8^{\text {a }}$ série - $1^{0}$ bimestre: 4 temas principais em 4 situações de aprendizagem & $n^{0}$ /aulas \\
\hline $1^{\circ}$ Imperialismo e Neocolonialismo no século XIX. & 1 aula \\
\hline $2^{\circ}$ A Primeira Guerra Mundial. & 2 aulas \\
\hline $3^{\circ}$ A Revolução Russa e o Stalinismo. & 1 aula \\
\hline $4^{\circ}$ A República no Brasil. & 3 aulas \\
\hline Total de aulas no $1^{\circ}$ bimestre & 7 aulas \\
\hline
\end{tabular}

Fonte: CIAMPI et al. 0 currículo bandeirante: a Proposta Curricular de História no estado de São Paulo Revista Brasileira de História, São Paulo, v. 29, n 58, 2009, p. 378-379. 
QUADRO 2: Proposta Curricular do Estado de São Paulo: História - Ensino Médio

\begin{tabular}{|c|c|}
\hline $1^{\text {a }}$ série - $1^{\circ}$ bimestre: 6 temas principais em 6 situações de aprendizagem & $n^{0}$ laulas \\
\hline $\begin{array}{l}10 \text { Problematizando a Pré-História. } \\
\text { - Tema: Pré-História }\end{array}$ & 4 aulas \\
\hline $\begin{array}{l}2^{\circ} \text { As fontes do conhecimento sobre a Pré-História. } \\
\text { - Tema: Pré-História }\end{array}$ & 1 aula \\
\hline $\begin{array}{l}3^{\circ} \text { A Pré- História sul-americana, brasileira e regional. } \\
\text { - Tema: Pré-História }\end{array}$ & 1 aula \\
\hline $\begin{array}{l}4^{0} 0 \text { Oriente Próximo e o surgimento das primeiras cidades. } \\
\text { - Tema: Civilizações do Oriente Próximo: } 0 \text { surgimento da escrita }\end{array}$ & 1 aula \\
\hline $\begin{array}{l}5^{0} \text { Egito e Mesopotâmia } \\
\text { - Tema: Civilizações do Oriente Próximo: o surgimento da escrita }\end{array}$ & 7 aulas \\
\hline $\begin{array}{l}\mathbf{6}^{\mathbf{0}} \text { Hebreus, fenícios e persas. } \\
\text { - Tema: Civilizações do Oriente Próximo: o surgimento da escrita }\end{array}$ & 2 aulas \\
\hline Total de aulas no $1^{\circ}$ bimestre & 16 aulas \\
\hline $2^{\text {a }}$ série - $1^{0}$ bimestre: 4 temas principais em 4 situações de aprendizagem & $n^{0}$ laulas \\
\hline $\begin{array}{l}1^{0} \text { Que mundo é esse? } \\
\text { - Conteúdo/tema: Renascimento Cultural }\end{array}$ & 1 aula \\
\hline $\begin{array}{l}2^{\circ} \text { As indulgências e os protestantes. } \\
\text { - Tema: Reforma Religiosa }\end{array}$ & 2 aulas \\
\hline $\begin{array}{l}\text { 30 A Utopia, o Príncipe e a Cocanha } \\
\text { - Tema: Absolutismo }\end{array}$ & 1 aula \\
\hline $\begin{array}{l}4^{\circ} \text { Interações culturais. } \\
\text { - Tema: Encontro entre os povos europeus, africanos, asiáticos e americanos }\end{array}$ & 2 aulas \\
\hline Total de aulas no $1^{\circ}$ bimestre & 6 aulas \\
\hline $3^{\text {a }}$ série - $1^{0}$ bimestre: 4 temas principais em 4 situações de aprendizagem & $n^{0}$ laulas \\
\hline $\begin{array}{l}1^{0} \text { Imperialismos, Gobineau e o racismo. } \\
\text { - Tema: Imperialismos }\end{array}$ & 1 aula \\
\hline $\begin{array}{l}2^{0} \text { "As bombas inteligentes" } \\
\text { - Tema: Primeira Guerra Mundial }\end{array}$ & 1 aula \\
\hline $\begin{array}{l}3^{\circ} \text { A Revolução Russa e o trabalho. } \\
\text { - Tema: Revolução Russa }\end{array}$ & 2 aulas \\
\hline $\begin{array}{l}4^{\mathbf{0}} \text { Antissemitismo nazista em Mein Kampf } \\
\text { - Tema: Totalitarismos (Stalinismo e Nazifascismo) }\end{array}$ & 1 aula \\
\hline Total de Aulas no $1^{\circ}$ bimestre & 5 aulas \\
\hline
\end{tabular}

Fonte: CIAMPI et al. 0 currículo bandeirante: a Proposta Curricular de História no estado de São Paulo. Revista Brasileira de História, São Paulo, v. 29, nº 58, 2009, p. 379-380. 
Nesse sentido, a proposta se constitui com um rol de conteúdos fixos que pode limitar as iniciativas criativas dos professores no interior das escolas, já que não é uma proposta de adesão opcional, como o documento eventualmente parece sugerir, mas obrigatória, uma vez que está diretamente vinculada ao desenvolvimento de determinadas habilidades para obtenção de melhores resultados no Sistema de Avaliação do Rendimento Escolar do Estado de São Paulo (Saresp); resultados pelos quais os professores são diretamente responsabilizados.

Ademais, do ponto de vista estritamente pedagógico, a proposta curricular São Paulo Faz Escola parece ferir alguns preceitos elementares da tão propalada "autonomia escolar". Azanha (1993), discutindo exatamente essa questão, muito antes dessa proposta, afirmava que:

Sem liberdade de escolha, professores e escolas são simples executores de ordens
e ficam despojados de uma responsabilidade ética pelo trabalho educativo. Nesse
caso professores seriam meros prestadores de serviços de ensino. De quem até
se pode exigir e obter eficiência, mas não que respondam, eticamente, pelos
resultados de suas atividades. (AZANHA, 1993, p. 14)

Desse modo, escolas e professores parecem possuir autonomia apenas para executar uma proposta pronta e ser responsabilizados pelo eventual fracasso. Para Bittencourt (2010), trata-se de tolher a autonomia intelectual do professor, reduzindo-o a "mero executor de tarefas de preparação do aluno para a realização de uma avaliação cujo propósito é fornecer índices que apresentem uma melhoria da qualidade de ensino da escola pública paulista" (BITTENCOURT, 2010, p. 560).

Não por acaso, o site do São Paulo Faz Escola traz no campo "Avaliação" informações sobre o Índice de Desenvolvimento da Educação do Estado de São Paulo (Idesp), o Saresp 2009 e 2010, o Exame Nacional do Ensino Médio (Enem) 2010 e o "Dia do Saresp" - com análises e comentários de assessores e consultores de diferentes áreas sobre os resultados do Saresp 2009 -, destinados a embasar reflexões dos professores durante o Horário de Trabalho Pedagógico Coletivo (HTPC) que se desdobrem em ações para obter melhores resultados nas avaliações.

Essa problemática dos limites de atuação do professor em sala de aula está atrelada à questão do bônus salarial, uma criação do projeto São Paulo Faz Escola. A lei complementar no. 1.078, de 17 de dezembro de 2008, criou a Bonificação por Resultados (BR), a ser paga aos servidores em efetivo exercício na Secretaria da Educação do Estado de São Paulo, decorrente do cumprimento de metas previamente estabelecidas, visando à melhoria e ao aprimoramento da qualidade 
do ensino público paulista. Seu artigo $1^{\circ}$ informa que a BR constitui prestação pecuniária eventual, desvinculada dos vencimentos ou do salário do servidor, que a perceberá de acordo com o cumprimento de metas fixadas pela administração em seu artigo $2^{\circ}$; que não integra nem se incorpora aos vencimentos, salários, proventos ou pensões para nenhum efeito e não será considerada para cálculo de qualquer vantagem pecuniária ou benefício. "Tem de ser um incentivo para valorizar todo e qualquer esforço da escola. Se conseguiu melhorar $10 \%$, isso tem, sim, de ser valorizado", afirmou a então Secretária de Educação em entrevista ao jornal O Estado de São Paulo (CAFARDO, 2008), no dia em que completava um ano no cargo.

À época, foram disponibilizados entre $\mathrm{R} \$ 500$ milhões e $\mathrm{R} \$$ 700 milhões para serem distribuídos aos funcionários, que poderiam receber até o equivalente a três salários a mais. $\mathrm{O}$ bônus seria concedido em fevereiro, quando poderiam ser comparadas as notas em avaliações externas, como o Saresp. A porcentagem a ser recebida seria de acordo com a meta traçada pela secretaria para cada escola, segundo o Idesp. Esse indicador varia de 0 a 10 e leva em conta o desempenho dos estudantes nas provas e o fluxo escolar (quantidade de alunos com a idade correta em cada série). Foi considerável a diferença dos valores pagos em 2008 (referentes ao período anterior à implantação da proposta) e em 2009 e 2010 (após a implantação) aos professores?.

Ainda quanto aos conhecimentos/conteúdos disciplinares prescritos pela Secretaria da Educação, consta na proposta que se trata de "tornar a escola um lugar privilegiado para o desenvolvimento do pensamento autônomo, que é condição para uma cidadania responsável" (SÃO PAULO, 2008a, p. 10), através de uma educação de qualidade para atender aos objetivos sociais. Informa, também, que "procura estabelecer elos entre os conhecimentos culturais socializados pela escola e as indicações de procedimentos organizados didaticamente" (SÃO PAULO, 2008a, p. 6), sem, no entanto, explicitar o que entende por "conhecimentos culturais socializados", do mesmo modo que não especifica o significado de cidadania, como se houvesse consenso acerca desses conceitos ou noções.

Tal imprecisão conceitual remete a uma concepção naturalizada e universal de conhecimento e currículo, identificandoos como parte de um processo natural de aperfeiçoamento e de democratização, com tendência a negar os diferentes significados que lhes são atribuídos historicamente. Tal retórica opera como freio a qualquer tipo de indagação questionadora, já que, ao se apresentar como um investimento desinteressado guiado por propósitos universais, desconsidera as arenas políticas nas quais qualquer reforma 
educacional se constitui e se autodefine a partir das variadas relações estabelecidas entre a escolarização e a sociedade.

Diferentemente de outras propostas curriculares que reivindicam, por meio de seus discursos, que lhes seja conferida a experiência de fundação de um novo momento na educação, pelo sentido de ruptura que seus agentes procuram estabelecer entre a sua atuação institucional e a do momento anterior, a do São Paulo Faz Escola se legitima pela ideia de continuidade, mas, paradoxalmente, promove profundas alterações em relação à disciplina de história, pautadas em posicionamentos teórico-metodológicos diametralmente opostos às propostas curriculares paulistas das décadas de 1980 e 1990 e mesmo em relação aos PCNs de 1997.

No entanto, se não representa uma novidade, como se explica uma nova proposta curricular? No que essa proposta curricular se distancia das anteriores, das intervenções institucionais do período anterior, implantadas a partir da década de 1980 e que buscaram associar à sua atuação administrativa a ideia de mudança?

O projeto, ao construir um discurso de que está apenas retomando e reordenando o que já existe, ou seja, identificando e incorporando as práticas de gestão escolar e de sala de aula já existentes, as orientações para a área de história estabelecidas pelos PCNs e pela Lei de Diretrizes e Bases da Educação Nacional (LDB) de 1996 e extraindo as competências e as habilidades da matriz do Enem, parece negar que, efetivamente, esteja construindo e implantando uma proposta curricular de história diferente da dos PCNs, centrada em eixos temáticos baseados em conteúdos históricos.

Com relação à organização dos conteúdos de história, a lógica que organiza o Caderno do Professor é diferente dos critérios utilizados pelos PCNs no que diz respeito ao saber histórico escolar, pelo menos sob dois aspectos: com relação à própria organização de conteúdos e à concepção/representação sobre o papel do professor na ação docente.

Os PCNs, como se sabe, baseiam-se em eixos temáticos organizados a partir de problemáticas sociais amplas, desdobrados em subtemas. A opção por oferecer um amplo conjunto de conteúdos, contemplada nos subtemas (ou a partir dos subtemas), incentivaria o professor de história a fazer seleções de conteúdos e conceitos e intervenções pedagógicas, privilegiando-se, assim, a reflexão e a autonomia docente. Diferentemente, a forma como o Caderno do Professor da proposta curricular São Paulo Faz Escola procura dirigir minuciosamente cada passo da atuação docente através das Orientações de Atividades para a gestão da aprendizagem na sala da 
aula - estruturadas a partir da sondagem e da sensibilização, do tempo previsto para o desenvolvimento de cada atividade, da seleção de temas e conteúdos, das competências e das habilidades, das estratégias, dos recursos materiais e das formas de avaliação e de recuperação - sinaliza para uma tentativa de controlar passo a passo a ação dos docentes.

Nas orientações sobre os conteúdos do bimestre e a duração estimada para cada situação de aprendizagem, localizadas na ficha do caderno, o professor é convocado a "realizar mudanças para melhor adequar as propostas à sua experiência docente, às classes de alunos e às condições de trabalho" (SÃO PAULO, 2008a, p. 8) ou a estabelecer previsões de tempo para as atividades, muito embora a ficha do caderno já estabeleça o tempo para o desenvolvimento de cada uma delas. Apesar de reforçar a necessidade de o professor assumir tal responsabilidade considerando as especificidades locais (escola, turmas, condições de trabalho), nota-se que resta muito pouco espaço para o professor fazer outras escolhas e refletir sobre o conteúdo mínimo, que deve ser aplicado de forma compulsória.

Por outro lado, chama a atenção a ênfase que a proposta coloca no deslocamento de foco: do ensino para a aprendizagem. O plano do professor deve indicar o que o aluno vai aprender, e não exatamente o que o professor vai ensinar. Resta, no entanto, o seguinte questionamento: Como construir a chamada "comunidade aprendente" a partir de uma proposta construída por "técnicos" sem nenhuma discussão anterior com os professores e sem que haja qualquer identidade entre os envolvidos no trabalho pedagógico e a apropriação feita pela Secretaria da Educação?

Outro ponto problemático com referência à metodologia é a concepção de situação de aprendizagem. Nos textos, surgem eventualmente como sinônimos: temas, situações de aprendizagem e conteúdos. Há uma diferenciação nos materiais referentes ao Ensino Fundamental e ao Ensino Médio. Assim, para o Ensino Fundamental, no sumário e no texto propriamente dito, consta "situação de aprendizagem", mas, na ficha do Caderno do Professor, aparece "tema". Já para o Ensino Médio, são usados indistintamente: temas, situações de aprendizagem ou conteúdos.

Essa constatação nos remete a pensar numa possível "desarticulação" entre as diferentes equipes de trabalho, ou seja, entre a equipe pedagógica que escreveu o documento geral, as equipes das disciplinas específicas e as de cada nível de ensino da educação básica. Essa hipótese sugere fragilidade e/ou inconsistência na estrutura e na reflexão epistemológica e metodológica da equipe gestora do projeto. 


\section{DAS CONCEPC̣ÕES DE EDUCAÇ̃̃O}

As reformas curriculares podem ser entendidas como resultado de lutas para produzir e institucionalizar determinadas identidades pedagógicas, processo no qual são mobilizados os mais diferentes recursos humanos, materiais e simbólicos. Como afirma Lopes (2002, p.146):

As propostas oficiais inseridas em uma dada reforma visam organizar um discurso legitimado e legitimador de determinadas orientações curriculares, capaz, portanto de institucionalizar determinadas relações de poder, bem como construir processos de controle ou regulamentação social.

É o que observamos pela análise de uma das matrizes organizadoras da proposta São Paulo Faz Escola, o currículo por competências, que é justificado pelo avanço tecnológico e o crescente acúmulo de conhecimentos (SÃO PAULO, 2008a, p. 7), pela necessidade de formar futuros adultos "preparados para exercer suas responsabilidades (trabalho, família, autonomia, etc)" (SÃO PAULO, 2008a, p. 8) ou para que as camadas mais pobres, em especial, tenham a "oportunidade real de aprendizado para inserção no mundo de modo produtivo e solidário" (SÃO PAULO, 2008a, p. 5), o que se traduz no deslocamento do "foco do ensino para o da aprendizagem, e não é por acaso que sua filosofia não é mais o da liberdade de ensino, mas o do direito de aprender" (SÃO PAULO, 2008a, p. 9).

Desse modo, os mentores da proposta aqui discutida alegam que a unidade do São Paulo Faz. Escola se dá não pelo estabelecimento do que deve ser ensinado, mas pelo que todos deverão ter aprendido no fim do processo, um conjunto básico de competências, o que garantiria a diversidade e a heterogeneidade do povo brasileiro na escola que se pretende democrática. Paradoxalmente, essa argumentação resultou nos Cadernos do Professor e do Aluno, que, como já demonstrado, pautam-se na prescrição e no controle das práticas e numa organização tradicional, linear e evolutiva de conteúdos.

O currículo por competências ${ }^{10}$ liga-se a duas tradições pedagógicas. A primeira origina-se dos trabalhos de Piaget e da concepção hegemônica presente na reforma curricular francesa, popularizada para o campo da formação de professores no Brasil pelos trabalhos de Perrenoud. A segunda vem da tradição americana da eficiência social de cunho comportamental. Essa segunda tradição, segundo Elizabeth Macedo (2002), tem predominado nos documentos curriculares, especialmente no que se refere às finalidades sociais da escolarização, em que escola, conhecimento e mercado de trabalho estão fortemente relacionados. 
$\mathrm{Na}$ tradição francesa, competência implica saber mobilizar conhecimentos e qualidades para resolver um problema dado. É também esse o sentido atribuído por Perrenoud (2000) à noção de competências ao defini-las como "esquemas de mobilização dos conhecimentos" (PERRENOUD, 2000, p. 10). Deseja o autor afastar entendimentos equivocados dessa noção: seja como sinônimo da pedagogia por objetivos, de mero desempenho ou uma faculdade genérica de qualquer mente humana.

Competência é, portanto, a capacidade de agir de forma eficaz em um determinado tipo de situação, apoiada em conhecimentos, mas sem limitar-se a eles. Assim, para enfrentarmos uma situação, colocamos em ação vários recursos cognitivos, entre os quais, os conhecimentos. As competências não são, em si mesmas, conhecimentos, "elas utilizam, integram ou mobilizam os conhecimentos" (PERRENOUD, 2000, p. 10). As competências são, para Perrenoud (1999, p.8), "complexas operações mentais cuja orquestração só pode construir-se ao vivo, em função tanto do seu saber e de sua perícia quanto de sua visão da situação".

Conhecimento e competências não se opõem, completamse, afirma o autor. O que pode haver entre eles é um conflito de prioridade, sobretudo com relação ao tempo do trabalho em sala de aula. O que está em jogo é o debate entre duas visões de currículo. Uma defendendo a acumulação mais ampla de conhecimentos, sem preocupar-se com sua mobilização em determinada situação, esperando, ou melhor, confiando que a construção das competências ocorrerá na formação profissional ou no próprio processo de vida pessoal. A outra posição é a de Perrenoud, que defende limitar a quantidade de mobilização de conhecimento em situação complexa, provocando sua integração operacional em uma competência, o que implica mais tempo para desenvolvê-la na prática pedagógica. Essa abordagem por competência é por muitos considerada uma "queda de nível" (PERRENOUD, 1999, p. 16).

Vale ressaltar a colocação de Macedo (2002), bastante esclarecedora na compreensão do significado de competência: a dificuldade "parece residir em como as experiências escolares podem ser planejadas para construir competências situacionais. Defendo que tentativas de planejamento curricular têm afastado a noção de competência da complexidade que a caracteriza, instrumentalizando-a" (MACEDO, 2002, p. 120). Esta descomplexificação da noção de competência provoca, no entendimento dessa autora, um hiato entre competência e desempenho, transformando aquela em condição para este. Nesse sentido, o desempenho certificaria a competência, fazendo 
com que um planejamento curricular centrado em competências se desenvolvesse tendo em vista certo conjunto de desempenhos.

Segundo a tradição americana, quando as competências são tratadas como ações gerais, retirando-se delas o seu caráter contextual, acaba-se por aproximar a noção de competência à de desempenho, aspecto observável tanto em documentos do MEC como na proposta curricular São Paulo Faz Escola.

$\mathrm{Na}$ década de 1970, a racionalidade tyleriana ainda continuava a influenciar a prática curricular brasileira. Um dos efeitos dessa racionalidade foi a movimentação em torno do currículo por competência, da tradição americana, que traz embutida a ideia de que o currículo é fundamentalmente um plano de atividades de ensino, ou seja, uma lista de resultados esperados em consequência de um processo de instrução. A concepção de currículo como listagem de produtos desejados herda das abordagens comportamentais a importância atribuída à definição precisa de objetivos, ou seja, dos comportamentos esperados e dos produtos a serem medidos.

No currículo por competências, surgido nos anos de 1970, o conceito de objetivos comportamentais é substituído pela ideia de competência, segundo a tradição americana. Desse modo, à semelhança dos objetivos comportamentais, as competências são entendidas como comportamentos mensuráveis e, portanto, cientificamente controláveis. Nesse tipo de currículo, a organização curricular faz com que o conhecimento e as disciplinas escolares sejam subsumidos às competências, às habilidades e às tecnologias a serem adquiridas pelos alunos. Ainda que, por muitas vezes, as competências funcionem a serviço do ensino das disciplinas acadêmicas, o currículo por competências, nessa tradição, tem por princípio a organização do currículo segundo módulos de ensino que transcendem as disciplinas.

É o que podemos observar na proposta curricular São Paulo Faz Escola, com a ênfase na competência leitora e escritora para todas as disciplinas, embora o projeto afirme respeitar as especificidades de cada uma destas. No texto da proposta, isso se justifica:

[...] em virtude da centralidade da linguagem no desenvolvimento da criança e do adolescente (...). Só por meio dela será possível concretizar a constituição das demais competências, tanto as gerais como aquelas associadas à disciplina e temas específicos. Para desenvolvê-la é indispensável que seja objetivo de aprendizagem de todas as disciplinas do currículo, ao longo de toda escolaridade básica. (SÃO PAULO, 2008a, p. 18, grifo nosso)

O grafocentrismo da proposta São Paulo Fą. Escola evidencia a compreensão do domínio de leitura e escrita como "a competência das 
competências", colocando todas as disciplinas escolares como penduricalhos curriculares a serviço da competência soberana, sob o pretexto da

[...] centralidade da linguagem, mas não seria mais correto justificar a linguagem como aquela que constitui as diversas formas de saberes, entre elas a escrita e a leitura? A linguagem não é um meio para acessar o mundo nem um fim onde o mundo só poderia ser pensando nela mesma, mas uma passagem ou ainda um jogo entre diversos vocabulários a tentar lidar com o mundo. (CIAMPI et al., 2009, p. 373)

Desse modo, as atividades constantes nos Cadernos do Aluno - História têm o evidente propósito de treinar para as competências leitora e escritora, descaracterizando a especificidade do conhecimento histórico. Em história, como se sabe, identificar a autoria de um texto é mais do que localizar o "sujeito do ato da fala", mas, sim, compreender como alguém, no seu tempo e a partir de seu espaço, elabora determinada visão de mundo e que, por isso, deve ser questionada como realidade linguística tal e qual. Quando se reduzem as competências à leitura e à escrita de textos em diversas áreas, há a dificuldade de compreender como as competências das áreas podem favorecer melhores leitura e escrita de textos.

Por outro lado, essa centralidade na área da língua portuguesa, com a consequente descaracterização da disciplina história, nos remete à discussão da noção de interdisciplinaridade, sobre a qual há razoável debate teórico. Nos PCNs, essa concepção epistemológica se apresenta na forma de Temas Transversais, que atravessam as diferentes disciplinas escolares, mantidas em seu status de eixo vertebrador do currículo escolar. Já na proposta aqui discutida, à disciplina língua portuguesa é atribuído o papel estruturador do currículo, em torno da qual orbitam as demais disciplinas escolares, como atestam os documentos oficiais da Secretaria de Educação de São Paulo.

Entendemos que, nas práticas interdisciplinares, as especificidades das disciplinas não devem ser perdidas, concordando com Bittencourt (2004, p. 256), para quem:

É fundamental o professor ter profundo conhecimento sobre sua disciplina, sobre os conceitos, conteúdos e métodos próprios do seu campo de conhecimento, para poder dialogar com os colegas de outras disciplinas. Os recortes de conteúdos de acordo com problemáticas comuns, a seleção dos conceitos para serem aplicados e aprofundados, enfim, a organização e sistematização de informações, que possam se integrar e fornecer aos alunos uma visão de conjunto do objeto do conhecimento são possíveis apenas se houver domínio por parte de especialistas das áreas. Essa condição é a garantia da preservação de um conhecimento escolar sem superficialidade, que aborde temas interdisciplinares em profundidade. Cada disciplina, no processo da 
constituição de um conhecimento interdisciplinar, tem uma contribuição específica, e, nesse sentido, a exigência ocorre em sentido oposto, aparentemente paradoxal. A interdisciplinaridade exige do docente um aprofundamento do seu campo específico de conhecimento, da sua disciplina escolar, e ao mesmo tempo desencadeia um trabalho metodológico conjunto. Conteúdos específicos são ensinados com um método comum a todas as disciplinas.

Entendemos que não se faz interdisciplinaridade fragmentandose o saber ou subordinando-se uma disciplina escolar a outra supostamente mais importante, criando-se uma irreal e inverídica oposição entre esses saberes, como se fossem opostos ou incompatíveis, que é o que apresenta a proposta curricular São Paulo Faz Escola.

\section{DA CONCEPC̣ÃO DE HISTÓRIA}

Desde o início da implantação da proposta São Paulo Fą Escola, com o Jornal do Aluno, a concepção grafocêntrica ficou evidente. Na publicação destinada à $5^{\mathrm{a}}$ e à $6^{\mathrm{a}}$ série, por exemplo, a seção de história traz trechos da famosa Carta de Pero Vaz de Caminha (SÃO PAULO, 2008b, p. 330-31), seguidos de algumas questões de "interpretação de texto", sem maiores reflexões sobre o tempo histórico.

1. O texto apresenta algumas características dos primeiros indígenas avistados pelos portugueses. De que forma Caminha os descreve? Utilize as informações do texto para construir sua resposta.

2. Como foi tratada a questão da religiosidade das populações indígenas pelo autor da carta? Justifique sua resposta. (SÃO PAULO, 2008b, p. 31)

O mesmo procedimento pode ser observado no Caderno do Aluno da $6^{a}$ série, volume 1, na Situação de Aprendizagem 4, sobre o Renascimento Cultural e Científico. Depois de um brevíssimo texto de 10 linhas "escrito especialmente para o São Paulo Faz Escola" (SÃO PAULO, 2009b, p. 33), seguem exercícios: "1. Escreva os três nomes dos artistas renascentistas citados no texto" e "2. Pesquise no seu livro didático, em enciclopédias ou em livros de apoio o significado das seguintes expressões: Renascimento cultural e científico, Baixa Idade Média e Afrescos" (SÃO PAULO, 2009b, p. 33). Na sequência, como lição de casa, nova pesquisa de palavras: "racionalismo", "humanismo", "antropocentrismo" e "teocentrismo". Na pesquisa em grupo, recomenda-se procurar no dicionário o significado da palavra "biografia", o que se desdobrará em pesquisas sobre Michelangelo Buonarroti, Rafael Sanzio e Leonardo da Vinci. No fim, seguem três questões de múltipla escolha, nas quais é necessário identificar 
"cidades italianas" como as principais referências do renascimento; "Vaticano" como o lugar onde fica a Capela Sistina; e "humanismo" como uma das características do renascimento. Como se percebe pela concepção qualitativa da interpretação de texto, são atividades que não exigem um professor de história com formação na área, capaz de promover reflexões sobre diferentes temporalidades históricas e estabelecer relações entre cultura, política, economia e sociedade. Nesse sentido, pareceu-nos que ocorre uma desqualificação desse profissional, uma vez que qualquer indivíduo sem conhecimentos específicos, portando o Caderno do Professor, poderia proceder à simples verificação das respostas dos alunos.

Sendo assim, a aprendizagem de história fica reduzida à simples memorização, como se observa no Caderno do Aluno da $5^{a}$ série, volume 1 (SÃO PAULO, 2009a, p. 23). Ao lado de uma foto em cuja legenda podemos ler "Imagem do crânio fossilizado de Luzia", consta um exercício de múltipla escolha - que mais parece um jogo de adivinhação - em que se deve identificar o nome do achado arqueológico: a) Lúcia, b) Luísa, c) Luciana, d) Luzia e e) Luana. No mesmo bloco de exercícios e em outras lições e cadernos de outras séries, seguem atividades do mesmo teor, cuja única habilidade exigida, se tanto, é a memorização.

Somando-se à predominante noção de tempo histórico linear, evolutivo e eurocêntrico, já assinalada anteriormente, observa-se uma concepção de história que privilegia os grandes acontecimentos, o que se evidencia na seleção de temas canônicos para as situações de aprendizagem e dos grandes personagens, sujeitos históricos por excelência: de Montesquieu a frei Bartolomeu de Las Casas, de Churchill a Lorca - este que, como se sabe, foi fuzilado, e não morto em combate, como equivocadamente está registrado no Caderno do Aluno da $3^{\text {a }}$ série do Ensino Médio, volume 2 (SÃO PAULO, 2009d, p. 10).

A Situação de Aprendizagem 3 da $8^{a}$ série, no volume 1 do Caderno do Aluno, sobre A Revolução Russa e o Stalinismo, é bastante ilustrativa dessa concepção de história. Das dez páginas dedicadas a essa temática, seis são destinadas à pesquisa das biografias de Czar Nicolau II, Lênin, Leon Trotsky e Josef Stalin: nome completo, data e local de nascimento, história familiar, trajetória de vida, participação na revolução, data, local e causa da morte (SÃO PAULO, 2009c, p. 28-29). Curiosamente, o texto introdutório dessa lição sugere outra concepção que não a apresentada: "Não estamos, assim, sugerindo que a História seja feita apenas por grandes personagens que, 
sozinhos, determinaram o rumo dos acontecimentos, mas queremos revelar que essas figuras de destaque também fizeram parte do processo" (SÃO PAULO, 2009c, p. 26).

A uma concepção de educação que reduz a disciplina escolar história à condição de disciplina auxiliar, secundária e dispensável, ignorando a especificidade e a importância do conhecimento histórico, somam-se concepções de história e ensino que privilegiam a simples memorização, uma noção de tempo histórico linear e evolutivo, sujeitos históricos como grandes personagens e os chamados grandes acontecimentos como fatos históricos por excelência. Assim, constatou-se que a proposta desconsidera, além dos importantes embates historiográficos ocorridos ao longo do século XX de crítica a essa concepção de história, o profícuo debate acumulado no campo do ensino de história, com relevantes pesquisas e publicações desde, pelo menos, a década de 1980.

\section{CONSIDERAÇ̃̃ES FINAIS}

Inserida na cultura escolar da rede pública estadual do Estado de São Paulo, que se fragmenta em 5.355 escolas aproximadamente, a proposta curricular São Paulo Faz Escola procurou se instituir como padrão curricular obrigatório que considerasse as diferentes realidades físico-materiais das escolas, as idiossincrasias dos sujeitos envolvidos (professores, alunos, pais, funcionários), os processos sócio-históricos de cada localidade, suas formas de organização, enfim, os elementos que caracterizam as culturas escolares ${ }^{11}$ e que podem ter o efeito de uma barreira invisível e silenciosa para programas educacionais desse tipo.

No que se refere ao ensino de história, ademais, constatou-se que na proposta foi ignorado o fecundo debate que vem correndo nesse campo desde a década de 1980 - com inúmeras pesquisas e publicações e com experiências e práticas escolares bem-sucedidas -, obliterandose ações criativas em sala de aula, uma vez que todos os procedimentos sugeridos estão atrelados aos conteúdos, às atividades e à organização do tempo escolar unificados e previstos nos cadernos do Professor e do Aluno disponibilizados pelo projeto São Paulo Faz Escola.

Outro aspecto controverso no âmbito da São Paulo Faz. Escola é a questão da interdisciplinaridade ao colocar a disciplina língua portuguesa como eixo estruturador do currículo, relegando à disciplina história - e às demais - um papel acessório para o desenvolvimento das competências leitora e escritora, 
desconsiderando a especificidade do conhecimento histórico e criando uma oposição artificial entre os saberes deste e daquela ${ }^{12}$.

Afora algumas incongruências observáveis na proposta curricular São Paulo Faz Escola e aqui discutidas, cabe apontar a necessidade de ampliar as pesquisas sobre como vem ocorrendo sua execução no cotidiano escolar ${ }^{13}$, estudando-se as apropriações dos materiais didáticos da proposta por alunos e professores, um dos polos da "relação triangular" de que fala Chartier $(1991,1992,1996)$.

Relatos informais de professores em oficinas do GT de Ensino de História e Educação da Anpuh-SP e relatórios de alunos estagiários de licenciaturas em História trazem as notícias mais díspares sobre sua execução: há professores que seguem à risca os cadernos, outros que simulam sua utilização ou que o ignoram sobejamente; coordenadores e diretores que fazem vista grossa ao não uso desses materiais ou que exigem sua aplicação rigorosa; alunos que nem sequer levam os cadernos do Aluno no dia a dia ou que colam as respostas de sites da internet. Como lembra Forquim (1992, p. 32), existe diferença entre "aquilo que é pretendido e aquilo que é ensinado realmente. Pode-se, além disso, acrescentar que aquilo que é realmente aprendido, retido e compreendido pelos alunos não corresponde tampouco àquilo que os docentes ensinam ou creem ensinar", ou àquilo que os mentores e os autores da São Paulo Faz Escola acreditaram e acreditam estar implementando.

A cultura escolar, essa "caixa-preta" (GOODSON, 1997, p. 93), enigmática e, por vezes, insondável, é algo "que as sucessivas reformas só arranham ao de leve e que a elas sobrevive" (VIÑAOFRAGO, 2007, p. 87). Ignorá-la ou desprezá-la no âmbito das reformas educacionais pode acarretar fracassos na gestão da educação e produzir simulacros educacionais. Esse entendimento, a nosso ver, dá relevância às pesquisas sobre propostas curriculares, como a São Paulo Faz Escola, na perspectiva aqui adotada.

\section{REFERÊNCIAS}

AZANHA, José Mario Pires. Proposta Pedagógica e Autonomia da Escola. Cadernos de História e Filosofia da Educação. São Paulo, FEUSP, vol.1, n¹, 1993.

BRASIL. Secretaria de Educação Fundamental. Parâmetros Curriculares Nacionais: história, geografia. Brasília: MEC/SEF, 1997.

BITTENCOURT, Circe M. F. Ensino de história: fundamentos e métodos. São Paulo: Cortez, 2004. Livros didáticos de história: práticas e formação docente. In: SANTOS, Lucíola L. C. P. et al. (org). Convergências e tensões no campo da formação e do trabalho docente. Belo Horizonte, MG: UFMG, 2010, p. 560. Disponível em: <http://www.fae.ufmg.br/endipe/livros/ Livro_6.PDF>. Acesso em: 06 abr. 2013. 
BOIM, Thiago Figueira. O que e como ensinar: Proposta Curricular, Materiais Didáticos e Prática de Ensino nas escolas públicas do estado de São Paulo (2008-2009). 135 p. Dissertação (Mestrado do Programa Educação: História, Política, Sociedade) - Pontifícia Universidade Católica de São Paulo. São Paulo, 2010.

CAFARDO, Renata. Entrevista com Maria Helena Guimarães. O Estado de São Paulo, Estadão, 28/julho/2008. Disponível em: <http://vida-estilo.estadao.com.br/noticias/ geral,sao-paulo-apresenta-projeto-de-bonus,213010>. Acesso em: 02 fev. 2015.

CHARTIER, Roger. O mundo como representação. Estudos Avançados. SP: USP, no 11, vol. 5, jan-abr 1991.

. Textos, impressão, leituras. In: HUNT, Lynn (org.). A Nova História Cultural. São Paulo: Martins Fontes, 1992.

(org.). Práticas da Leitura. São Paulo: Estação Liberdade, 1996.

CIAMPI et al. O currículo bandeirante: a Proposta Curricular de História no estado de São Paulo. Revista Brasileira de História, São Paulo, v. 29, nº 58, 2009, 373 p.

FORQUIN, Jean-Claude. Saberes Escolares, Imperativos Didáticos e Dinâmicas Sociais. Teoria \& Educação, Porto Alegre, vol. 5. 1992.

FUNDAÇÃO VANZOLINI. Disponível em: < http://www.vanzolini.org.br/conteudo-76. asp?cod_menu=770\&cod_site=76\&id_menu=794>. Acesso em: 10 fev. 2014.

GOODSON, Ivor F. Currículo: teoria e história. Petropólis, RJ: Vozes, 1995.

. A construção social do currículo. Lisboa: Educa, 1997.

JULIA, Dominique. A cultura escolar como objeto histórico. Revista Brasileira de História da Educação. no 1, 2001, p.p. 9-44. Disponível em: <http://www.rbhe.sbhe.org.br/index.php /rbhe/article/view/273/281>. Acesso em: 02 mai. 2014.

LOPES, Alice Casimiro. Parâmetros Curriculares para o Ensino Médio: quando a integração perde seu potencial crítico. In: LOPES, Alice Casimiro; MACEDO, Elizabeth (org.). Disciplinas e integração curricular: história e políticas. Rio de Janeiro: DP\&A, 2002.

MACEDO, Elizabeth. Currículo e Competência. In: LOPES, Alice Casimiro; MACEDO, Elizabeth (org.). Disciplinas e integração curricular: história e políticas Rio de Janeiro: DP\&A, 2002. MUNAKATA, Kazumi. Livro, livro didático e forma escolar. In: DALBEN, Ângela et al. (org.). Convergências e tensões no campo da formação e do trabalho docente. Belo Horizonte: Autêntica, 2010, v. 1, p.p. 219-240. Disponível em: < http://www.fe.unicamp.br TEMPORARIOS/rpdialogo.PDF>. Acesso em: 02 mai. 2014.

PERRENOUD, Philippe. Construir as competências desde a escola. Porto Alegre: Artes Médicas, 1999.

Dez novas competências para ensinar. Porto Alegre: Artes Médicas Sul, 2000.

SÃO PAULO. Secretaria da Educação do Estado de São Paulo - SEE. Proposta Curricular do Estado de São Paulo: história. 2008a.

. Secretaria da Educação do Estado de São Paulo - SEE. Jornal do Aluno: São Paulo Faz Escola - Edição Especial da Proposta Curricular. 2008b.

. Secretaria da Educação do Estado de São Paulo - SEE. Caderno do aluno: ciências humanas e suas tecnologias - história. $5^{\text {a }}$ série, Ensino Fundamental, v. 1, 2009a.

Secretaria da Educação do Estado de São Paulo - SEE. Caderno do aluno: ciências humanas e suas tecnologias - história. $6^{a}$ série, Ensino Fundamental, v. 1, 2009 b.

. Secretaria da Educação do Estado de São Paulo - SEE. Caderno do aluno: ciências humanas e suas tecnologias - história. $8^{\mathrm{a}}$ série, Ensino Fundamental, v. 1, 2009c. 
Secretaria da Educação do Estado de São Paulo - SEE. Caderno do aluno: ciências humanas e suas tecnologias - história. $3^{\text {a }}$ série, Ensino Médio, v. 2, 2009d.

VIÑAO-FRAGO, Antonio. Sistemas Educativos, Culturas Escolares e reformas. Mangualde, Portugal: Edições Pedago, 2007.

VINCENT, Guy; LAHIRE, Bernard; THIN, Daniel. Sobre a história e a teoria da forma escolar. Educação em Revista, Belo Horizonte, v. 33, jun. 2001.

\section{NOTAS}

${ }^{1}$ Informação obtida durante a realização do Fórum de Graduação da Associação Nacional de História, seção São Paulo (Anpuh-SP), realizado em 17 de maio de 2008, para discussão da proposta curricular São Paulo Faz Escola, quando de sua implementação, com participação de professores da rede pública estadual de São Paulo e docentes das licenciaturas em História de universidades públicas e privadas.

${ }^{2}$ Disponível em: < http:/ / www.educacao.sp.gov.br/sao-paulo-faz-escola>. Acesso em: 02 fev. 2015.

${ }^{3}$ Língua portuguesa, história, educação física, artes, matemática, língua estrangeira moderna, geografia e ciências.

${ }^{4}$ Por exemplo: <http://ndiga.com/respostas-do-caderno-do-aluno-2013/>, <http:// www.linkatual.com/caderno-do-aluno.html>, <http://baianow.com/caderno-do-alunorespostas/> e <http://www.maisgratis.com.br/caderno-do-aluno-gabarito-e-respostas. html>. Acesso em: 10 fev. 2014.

${ }^{5}$ Disponível em: <http://www.educacao.sp.gov.br/portal/projetos/sao-paulo-faz-escola>. Acesso em: 10 fev. 2013.

${ }^{6}$ Disponível em: <http://www.vanzolini.org.br/conteudo-76.asp?cod_menu=770\&cod_ site=76\&id_menu=794>. Acesso em: 10 fev. 2014.

${ }^{7}$ Sobre a concepção subjacente à ideia de "heróis" responsáveis pela construção da história, discutiremos este assunto no último subitem deste artigo.

${ }^{8}$ Disponível em: < http://www.rededosaber.sp.gov.br/portais/AVALIA \%C3\%87\%C3\%83O/ DIADOSARESPNAESCOLA/tabid/1491/Default.aspx>. Acesso em: 10 fev. 2014.

${ }^{9}$ Uma professora da rede pública do estado de São Paulo, representante dos professores de história da Educação Básica na Anpuh-SP, informou que, em fevereiro de 2008 recebeu $\mathrm{R} \$ 275,00$ (pagamento referente ao exercício de 2007, portanto, anterior à implantação da proposta). Em 2009, recebeu a quantia de $\mathrm{R} \$ 3.433,94$ (referente ao exercício de 2008) e, em 2010, a quantia de $\mathrm{R} \$ 2.540,96$. Curiosamente, em 2011, recebeu apenas $\mathrm{R} \$ 67,75$ de bônus, enquanto alguns colegas na mesma escola nada receberam. A rede estadual paulista de educação, a maior rede estadual da América Latina, oferecia aos seus 162.941 professores de Educação Básica II em 2010 o salário-base de R\$1.500,00 por 40 horas semanais de trabalho. Atuam em salas com média de 40 a 60 alunos. Tendo geralmente de duas a três aulas semanais de história (no ciclo II), acabam atendendo a mais alunos e trabalhando com número de turmas maior que a média sugerida pelo Conselho Nacional de Educação (CNE) para equacionar o problema da superlotação das salas de aula.

${ }^{10}$ Independentemente da multiplicidade de significados que assume, a noção de competência apresenta-se como uma nova tecnologia de organização curricular, associada às ideias de transversalidade e de interdisciplinaridade. (MACEDO, 2002). 
${ }^{11}$ Viñao-Frago entende que seja mais adequado falar em culturas escolares, pois cada "estabelecimento docente tem, de forma mais ou menos acentuada, a sua própria cultura, as suas características peculiares. Não há duas escolas, dois colégios, institutos, universidades ou faculdades exatamente iguais, embora entre eles se possam estabelecer semelhanças" (VIÑAO-FRAGO, 2007, p. 95).

${ }^{12}$ Curiosamente, esse mesmo entendimento parece perdurar, como sugerem as resoluções $n^{\circ}$. 81 de 16 de dezembro de 2011 e no .2 de 18 de janeiro de 2013. Por meio destas, a Secretaria de Educação do Estado de São Paulo retirou o ensino de história (além de geografia e ciências físicas e biológicas) do $1^{\circ}$, do $2^{\circ}$ e do $3^{\circ}$ ano da Matriz Curricular dos anos iniciais do Ensino Fundamental e reduziu a presença da disciplina de história a $5 \%$ da carga horária no $4^{\circ}$ e no $5^{\circ}$ ano, restando apenas 100 horas de estudo de história numa carga total de 5.000 horas de estudos para as crianças entre 6 e 10 anos de idade.

${ }^{13}$ Nesse sentido, vale citar a pesquisa de mestrado de BOIM (2010).

Recebido: $27 / 02 / 2014$

Aprovado: 26/08/2014

Contato:

UNIFESP Campus Guarulhos

Estrada do Caminho Velho, 333 Bairro dos Pimentas

Guarulhos |SP|Brasil

CEP 07.252-312 
